\title{
PRIMARY RETICULOSARCOMA OF THE THYROID GLAND
}

\author{
L. RoberTs, M.B.(Sydney), F.R.C.S.(Eng.) \\ Senior Surgical Registrar, Royal Northern Hospital, London, N.7
}

PRIMARY reticulosarcoma of the thyroid is an uncommon condition; in the past ro years, however, increasing numbers of these cases have been recorded in the literature.

TABLE I

\begin{tabular}{|c|c|c|c|}
\hline Author & & & $\begin{array}{l}\text { No. of } \\
\text { Cases }\end{array}$ \\
\hline Dinsmore, Dempsey and Hazard, & 1948 & $\cdots$ & 8 \\
\hline Kellett and Sutherland, 1949 & $\cdots$ & . & 5 \\
\hline Dean, r949 $\quad \ldots \quad \ldots \quad \ldots$ & . & . & 2 \\
\hline Roualle, I950 & . & . & 2 \\
\hline Dick and Kellett, I95 I & . & . & 2 \\
\hline Scott, I952 $\ldots$ & - & . & 2 \\
\hline Brewer and Orr, I953 , . & . & . & 10 \\
\hline Walt, Woolner and Black, 1953 & . & . & 21 \\
\hline Kenyon and Ackerman, 1955 & . & . & 2 \\
\hline Lindsay and Dailey, I955 . & . & . & 8 \\
\hline Canney, $1956 \quad \ldots \quad$. & . & $\cdots$ & $\mathbf{I}$ \\
\hline Canklin and Gent, I957 $\ldots$ & $\because$ & $\cdots$ & $\mathbf{I}$ \\
\hline Cureton, Harland, Hosford and & Pike, & 1957 & 2 \\
\hline Rangström, $1957 \quad \ldots \ldots$ & . & & 8 \\
\hline Welch, Chesky \& Hellwig, $195^{8}$ & . & . $\ldots$ & 4 \\
\hline
\end{tabular}

Until recently many American writers doubted that primary reticulosarcoma of the thyroid occurred, considering such cases to be highly anaplastic small-cell carcinomas. There is little doubt, however, that this condition does exist and is distinct, histologically, from small-cell carcinomas. Walt, Woolner and Black examined the gross specimens and tissue slides from all 30 cases of small-cell malignant thyroid tumours seen at the Mayo Clinic from 1929-54. Twelve of these were considered to be small-cell carcinomas and I8 malignant lymphomas (reticulosarcoma). Upon reviewing the literature over the past Io years, 78 recorded cases of histologically proven reticulosarcoma have been found. One further case of lymphosarcoma of the thyroid is here reported.

\section{Case Report}

Miss J.F., at. 57, was referred to the Out-Patient Department in February 1959, complaining of a swelling in the neck. Two years before presenting she noticed a swelling in the left side of the neck, which remained for one week and then disappeared. Three months before presenting the swelling reappeared and persisted.
It fluctuated in size and on occasions caused slight dysphagia and dysphonia, but no dyspnœa or stridor. She had lost some weight, but was not sure how much. She had a chronic cough (smokes Io cigarettes per day), but there was no recent alteration in this.

On examination. Middle-aged female in apparent good health, but with a notable brassy cough. There was a soft, probably cystic swelling in the left lobe of the thyroid gland which moved on swallowing. There was no enlargement of the right lobe, no palpable thrill or audible murmur and there were no signs of thyrotoxicosis. The trachea was deviated to the right. Cervical lymph glands were not palpable.

An X-ray of the chest and neck taken on February 12 , 1959, was reported on as follows: "The trachea is bowed over to the right as it enters the thorax and there is some slight compression of its diameter. This appearance could be due to an enlarged thyroid, which would also account for the swelling in the rest of the neck. One cannot, of course, differentiate it from other tumours situated in the same position'. She was seen in the Out-Patient Department on several occasions during the following six weeks and on one occasion the swelling was not palpable and the trachea was midline. She was admitted on April 12, 1959. The swelling in the left lobe of the thyroid was palpable, but was larger and felt more firm. The trachea was deviated to the right. There was no attachment to the surrounding structures, no cervical adenopathy and no signs of toxicity. Pulse rate $66 / \mathrm{min}$. B.P. $190 / 80$. Hb. $93 \%$, E.S.R. $5 \mathrm{~mm}$./hour, W.C.C. 6,000 p.c.mm., normal distribution.

Operation. On April 14, 1959, exploration of the thyroid gland was carried out. The left lobe of the thyroid was very large and nodular and the capsule was intact. The lower pole was soft, homogeneous, grey and very friable, which made mobilization difficult. The right lobe appeared normal. Left hemi-thyroidectomy was carried out. She made a rapid recovery and was discharged on April 30, 1959. The histological report by Dr. M. Peters was: "Virtually the whole of the parenchyma is replaced by proliferating comparatively adult lymphocytes, leaving only isolated epithelial cells and acini with traces of colloid stranded among them. Diagnosis: lymphosarcoma of thyroid '.

Following operation she was given a large field of irradiation to the neck and upper mediastinum. She has returned to work as a cleaner and remains very well. She was last seen on March 31, 1961. There has been no recurrence in the neck, no lymphadenopathy," no sign of metastases to other tissues and nothing to suggest gastro-intestinal secondary deposits.

\section{Clinical Features}

Clinical experience of this dise ase is very limited 


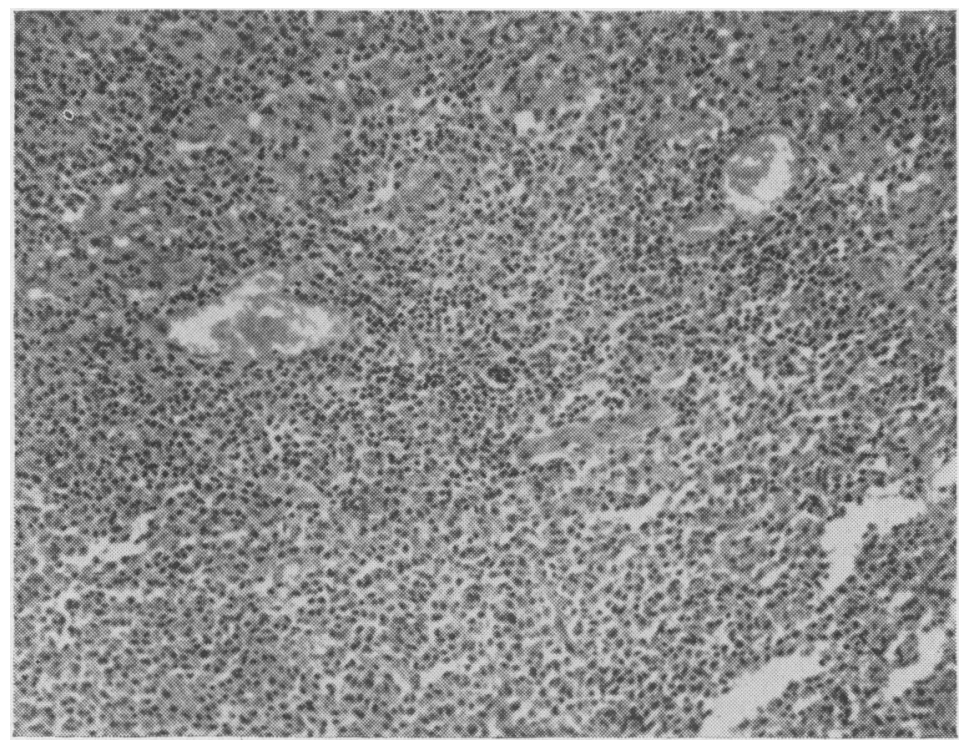

and a clinical diagnosis is very difficult to make; the disease is uncommon and there are no distinctive diagnostic features. It was not diagnosed in any of the 78 cases collected in Table $\mathrm{I}$. Middle-aged females are most commonly affected. The most frequent presenting symptom is a lump in the neck and there may be a past history of goitre. Less frequently patients complain of dysphagia, hoarse voice, dyspnœa or pain in the neck. Examination reveals a hard or firm enlargement of the thyroid, nearly always confined to one lobe. In late cases involvement of the surrounding structures occurs and the regional lymph glands may be palpable. The majority of cases are euthyroid and are diagnosed clinically as carcinoma, adenoma or nodular goitre, the correct diagnosis being made by histological examination of operation or biopsy specimens.

The treatment of this condition is by a combination of surgery and radiotherapy. The surgical procedure will vary from case to case, depending on $(a)$ pre-operative diagnosis, $(b)$ operation findings and $(c)$ frozen section biopsy report if this is requested. The majority of cases have either a total or subtotal hemithyroidectomy. Limited involvement of surrounding tissuc does not contraindicate operation and every attempt should be made to remove the primary growth. In advanced cases there is widespread local infiltration with involvement of vital structures, and surgery is limited to diagnostic biopsy. Following operation nearly all cases were given a course of deep $\mathrm{X}$-ray therapy. Reticulosarcoma is a radiosensitive tumour and all are agreed on the value of radiotherapy, in conjunction with surgical treatment, for this condition. In advanced cases treat- $\frac{c}{\omega}$ ment is by radiotherapy alone. The field of $\stackrel{+}{\rightarrow}$ irradiation should include the thyroid gland, the lower cervical lymph chains and the superior. mediastinum, the dosage suggested being 2,500 要 over three weeks.

Metastasis occurs to the cervical and mediastinal lymph glands and to distant organs. Notable ֶ among the latter sites is the gastro-intestinal tract $\stackrel{\mathbb{Q}}{\AA}$ and Dick and Kellett (I95I) made particular $\overrightarrow{\vec{B}}$ reference to this.

The over-all prognosis is poor and the majority of cases are dead within two years. However, a? number of long-term survivals have been recorded and Welch et al. (1958) found 15 cases surviving five years or more.

\section{Histology}

Primary reticulosarcoma of the thyroid can be divided histologically into three types: reticulum 의 cell sarcoma, lymphosarcoma and Hodgkin's $D$ disease, although not all of the aforementioned authors classified their tumours as such. Walt N et al. (I957) classified only three of their 2 I cases as mature lymphocytic lymphosarcomas, the re- 0 maining 18 cases were classified as immature $\tilde{\omega}$ lymphosarcomas, the histological appearance varying, by stages, from the mature lymphosarcoma ate one end to reticulum-cell sarcoma at the other. Welch et al. (1958) classified three of their five $\stackrel{\text { ? }}{?}$ cases as lymphoblastomas. On reviewing the 78 움 cases with regard to histological classification, it $\frac{O}{\mathbb{D}}$ is found that approximately one-third of the cases 


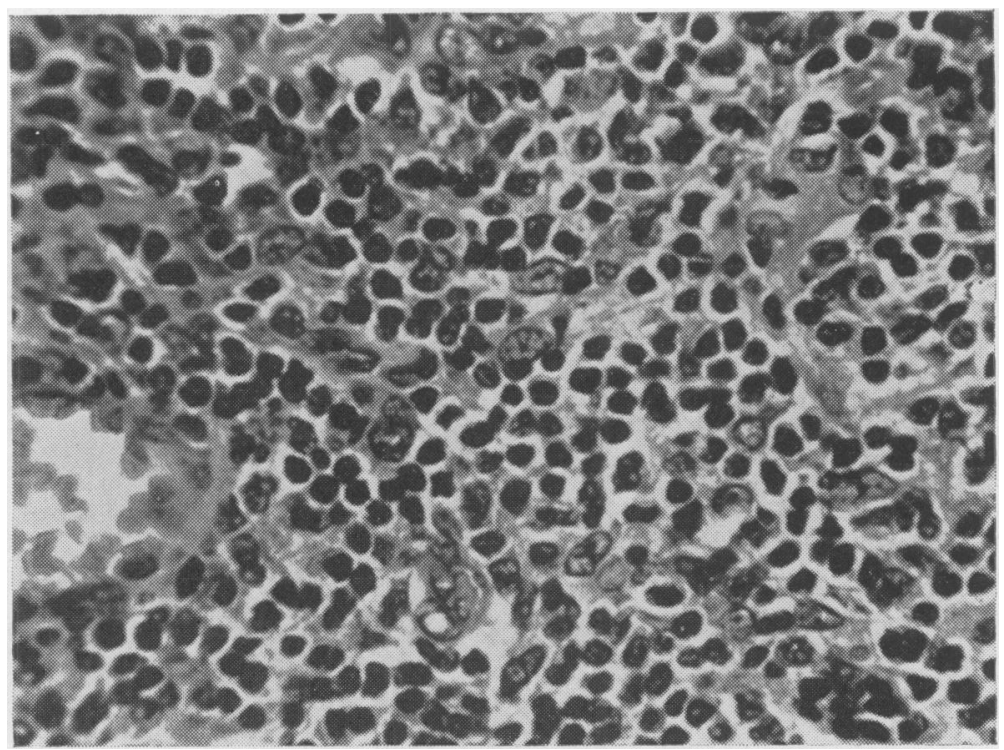

were lymphosarcoma, one-third were reticulumcell sarcoma and one-third werelymphoblastoma or immature lymphosarcoma, the latter group including those cases whose histological appearances lie between the former two types. Hodgkin's disease of the thyroid is very rare and no case was recorded.

\section{Relationship to Hashimoto's Disease}

The relationship between Hashimoto's disease and primary reticulosarcoma of the thyroid is discussed by several of the above authors and their conclusions vary from a denial of any relationship on the one hand to an acceptance on the other. Lindsay and Dailey (1955), who reported eight cases, stated that in seven of them the thyroid glands also showed the typical histological changes of Hashimoto's disease. A similar relationship was found by Rangström (1957) in his eight cases, Cureton et al. (1957) in their two cases and Kenyon and Ackerman (1955) in their two cases. These last authors consider that their second case may demonstrate the transition from the benign lymphoid tissue of Hashimoto's disease to the malignant reticulum-cell sarcoma. On the other hand, however, Walt et al. (1957) could find this relationship in only three of their 21 cases, the remaining 18 cases showing no histological evidence of Hashimoto's disease. Similarly, Dinsmore et al. (1949) mentioned the relationship in only one of their eight cases. Kellett and Sutherland (1949) described lymphoid hyperplasia in three of their cases where tumour-free tissue was available for study. However, they did not think these changes were part of a Hashimoto's disease. On examination of the 78 cases mentioned above, a positive relationship between the two conditions was recorded in 25 cases and a negative relationship in 27 cases. In the remaining cases no mention was made, one way or the other, of this point. Kellet and Sutherland's cases were equivocal and were not included. It is evident that the sex distribution and age group of the two conditions are the same, middle-aged females being most frequently affected. Although the total number of cases is small, and the individual series are smaller, the above findings suggest that there is a definite relationship between the two conditions, namely, that primary reticulosarcoma is more likely to develop in thyroid glands which are affected by Hashimoto's disease.

\section{Summary}

The literature on primary reticulosarcoma of the thyroid has been examined and one further case added.

The clinical features and histological types are discussed.

It is suggested that there is a definite relationship between Hashimoto's disease and primary reticulosarcoma.

I would like to thank Mr. K. Owen for permission to publish this case and for his help in preparing this paper. I would also like to thank Dr. M. Peters for the pathology report and the Pathology Department for photomicrographs. 


\section{REFERENCES}

Brewer, D. B., and ORR, J. W. (1953): Struma Reticulosa. A reconsideration of the Undifferentiated Tumours of the Thyroid, $\mathcal{F}$. Path. Bact., 55, 193.

CanNEY, R. L. (1956): Reticulosarcoma of the Thyroid Gland and Stomach, Brit. Y. Surg., 43, 376.

CANKLIN, S. D., and Gent, D. H. (1957): Lymphosarcoma of the Thyroid. Report of a case, Ann. intern. Med., 46, 784.

Cureton, R. J. R., Harland, D. H. C., Hosford, J., and PIKE, C. (1957): Reticulosarcoma in Hashimoto's Disease, Brit. Y. Surg., 44, 561.

Dean, G. S. (1949): Reticulum Cell Lymphosarcoma of the Thyroid Gland, Illinois Med. F., 95, 371.

DiCK, A., and KeLLeTT, H. S. (1951): Reticulosarcoma of the Thyroid Gland, Brit. F. Surg., 39, 257.

DiNSMORE, R. S., DEMPSEY, W. S., and HAZARD, J. B. (1949): Lymphosarcoma of the Thyroid, $\mathcal{Y}$. clin. Endocr., 9, 1043.

Kellett, H. S., and Sutherland, T. W. (1949): Reticulosarcoma of the Thyroid Gland, f. Path. Bact., 6r, 233.

KenYON, R., and ACKERMAN, L. V. (1955): Malignant Lymphoma of the Thyroid apparently arising in Struma Lym-

phomatosa, Cancer, 8, 964.
LindSAY, S., and DAILEY, M. E. (1955): Malignant Lymphoma of the Thyroid Gland and its relation to Hashimoto's Disease. A clinical and pathologic study of eight patients, F. clin. Endocr., 15, 1332.

RANGSTRÖM, S. (1957): Malignant Lymphoma of the Thyroid and its relation to Hashimoto's and Brill-Symmers' Disease, Acta chir. scand., I13, 185 .

Roualle, H. L. M. (1950): Malignant Disease of the Thyroid Gland, Ann. roy. Coll. Surg. Engl., 7, 67.

ScotT, G. B. D. (1952): The diagnosis of Reticulosarcoma of the Thyroid Gland, $\mathscr{Y}$. clin. Path., 5, 183 . WALT, A. J., WooLNER, L. B., and BLACK, B. M. (1957): Small-cell Malignant Lesions of the Thyroid Gland, $\mathcal{F}$. clin.
Endocr., 17, 45.

WelCh, J. W., CHESKy, V. E., and Hellwig, C. A. (1958) : Malignant Lymphoma of the Thyroid, Surg. Gynec. Obstet., ro6, 70. 